Int. J. Electrochem. Sci., 14 (2019) 7623 - 7630

\title{
Simultaneous Voltammetric Determination of Ascorbic Acid, Dopamine and Uric Acid by the Poly(alizarin yellow R)/GCE
}

\author{
Li Zhang ${ }^{*}$, Hongyan Wang, Jian Wu, Qiao Liu, Yanyan Zhu, Keying Zhang, Guang Zhu* \\ Anhui Key Laboratory of Spin Electron and Nanomaterials; School of Chemistry and Chemical- \\ Engineering, Suzhou University, Suzhou, Anhui 234000, People's Republic of China \\ *E-mail: suzhou univer 09@163.com, zhlisuzh@163.com,
}

doi: $10.20964 / 2019.08 .16$

Received: 16 January 2019 / Accepted: 18 May 2019 / Published: 30 June 2019

\begin{abstract}
A glassy carbon electrode (GCE) modified with the poly(alizarin yellow R) (PAYR) film was prepared by an electropolymerization method. Ascorbic acid (AA), dopamine (DA) and uric acid (UA) were determined by this electrode, and its electrocatalytic activity toward AA, DA and UA oxidation was clearly demonstrated. The separate oxidation peak potentials of 178, 115 and $293 \mathrm{mV}$ were found for AA/DA, DA/UA and AA/UA, respectively. The oxidation peak currents were linear with the respective compound concentrations, the linear ranges were $80 \mu \mathrm{M}$ to $2000 \mu \mathrm{M}$ (AA), $2.3 \mu \mathrm{M}$ to $17.5 \mu \mathrm{M}$ (DA) and $33 \mu \mathrm{M}$ to $330 \mu \mathrm{M}$ (UA), and the detection limits were $8.3 \mu \mathrm{M}, 0.42 \mu \mathrm{M}$ and $4.3 \mu \mathrm{M}$, respectively. Additionally, this electrode exhibited excellent performances characteristics including good selectivity, reproducibility and stability and was successfully used to detect DA in a real sample with satisfactory results.
\end{abstract}

Keywords: Alizarin yellow R, Ascorbic acid, Dopamine, Uric acid, Electropolymerization,

\section{FULL TEXT}

(C) 2019 The Authors. Published by ESG (www.electrochemsci.org). This article is an open access article distributed under the terms and conditions of the Creative Commons Attribution license (http://creativecommons.org/licenses/by/4.0/). 